\title{
Predictors of Renal Failure in Patients with Decompensated Liver Cirrhosis
}

\author{
Mohamed M. Abdo ${ }^{1^{*}}$, Nashaat M. Soliman²
}

Departments of ${ }^{1}$ Internal Medicine, and ${ }^{2}$ Endemic \& Infectious Diseases, Faculty of Medicine, Suez Canal University, Egypt

\begin{abstract}
Background: Renal failure is a challenging complication of liver cirrhosis. Patients with cirrhosis and renal failure are at high risk for death while awaiting transplantation. They also have an increased frequency of complications and reduced survival after transplantation. Aim: to evaluate the predictors of renal failure in patients with decompensated liver cirrhosis. Patients and Methods: The study included 86 patients with decompensated liver cirrhosis in Suez Canal University Hospital. Data were collected using a questionnaire that included personal data , full medical history, clinical examinations, Laboratory investigations included prothrombin time (PT), complete blood count $(C B C)$, serum creatinine, urea and uric acid, complete urine analysis, random blood glucose, alanine transaminase (ALT), aspartate transaminase (AST), serum direct and indirect bilirubin, serum albumin, total protein, and alkaline phosphatase, serum and urinary sodium, chemical and cytological assessment of ascetic fluid And at last pelvi-abdominal ultrasound and outcome measures [Child-Pugh and Model for End-stage Liver Disease (MELD) scores]. Results: There were statistically significant higher mean age, higher mean duration of hospital stay and higher mean MELD score in the studied patients with renal failure than the patients without renal failure $(p=0.001)$. Also, there were higher frequencies of smoker patients, patients with SBP, and patients with variceal bleeding in the studied patients with renal failure than in the patients without renal failure $(p=0.01)$. Significant predictors include age $>55$ years (odds ratio $(O R)=3.5)$, SBP $(O R=4.8)$, variceal bleeding $(O R=14.7)$, urine sodium $(O R=11.8)$, serum sodium ( $O R=7.9)$, and $M E L D$ score $>25(\mathrm{OR}=15.6)$. Conclusions: Low urinary and serum sodium, high bilirubin and MELD score are significant predictors of renal failure in patients with decompensated liver cirrhosis.
\end{abstract}

Keywords: Hepatorenal syndrome, kidney injury, Child-Pugh, MELD

\section{Introduction}

Renal failure is a challenging complication of liver cirrhosis ${ }^{(1)}$, and is one of the most important risk factors when liver transplantation is being considered. Patients with cirrhosis and renal failure are at high risk for death, while awaiting transplantation, and have an increased frequency of complications and reduced survival after transplantation, as compared with those without renal failure ${ }^{(2)}$. Hepatorenal syndrome (HRS) is one of the most dreaded complications of cirrhosis ${ }^{(3)}$. It predominantly occurs in patients with advanced liver disease, very rarely in conditions other than cirrhosis. About $20 \%$ of patients with cirrhosis and ascites are reported to develop HRS within a period of 1 year ${ }^{(4)}$. HRS is divided into two types: HRS type 1 shows a rapid deterioration of kidney function, whereas HRS type 2 progresses less dramatically ${ }^{(5)}$.

*Corresponding author:d_m.abdo2014@yahoo.com 
The prognosis of patients with HRS is poor. Papers reported median survival times of only approximately 3 months for unselected patients with both types of HRS. ${ }^{(6)}$ In patients with HRS type 1, the median survival is reported to be only 2 weeks, whereas it is considerably longer in patients with HRS type $2^{(3)}$. The current firstline treatment of HRS including vasoconstrictors (terlipressin, midodrine, octreotide) and albumin is probably effective in about two-thirds of patients ${ }^{(7)}$ and the response to treatment is associated with an improved survival ${ }^{(8)}$. However, despite treatment with vasoactive drugs, patients with HRS type 1 still have a dismal prognosis. Therefore, in most individuals, only liver transplantation provides a good long-term outcome. Most commonly, the 'Model for End-Stage Liver Disease (MELD)' is applied for this purpose ${ }^{(9,10)}$. Before the MELD score was established and validated ${ }^{(9,11)}$ the International Ascites Club had defined diagnostic criteria for $\mathrm{HRS}^{(5)}$. It has been shown that in a cohort of HRS patients, the type of HRS (type 1 vs. type 2) and the MELD score are the most important independent predictors of survival ${ }^{(6)}$.

There are many causes of renal impairment other than HRS in patients with cirrhosis, including glomerulonephritis, tubular necrosis, diabetic nephropathy, intake of nephrotoxic drugs, volume depletion due to hemorrhage, or use of diuretics and/or infectious complications ${ }^{(12,13)}$. According to the diagnostic criteria for HRS, these conditions must be ruled out before the diagnosis of $\mathrm{HRS}^{(5)}$. As the MELD score does not reflect the cause of kidney dysfunction, the type of renal disease might have an independent prognostic value in addition to the MELD score in unselected patients with cirrhosis and renal impairment and should influence the priority listing for transplantation. Therefore, in the current study, we analyzed the predictors of renal failure in consecutive patients with decompensated liver cirrhosis in a Tertiary Care University Hospital.

\section{Patients and Methods}

Eighty-six patients with decompensated liver cirrhosis were recruited from Internal Medicine department of Suez Canal University Hospital in the period from January 2012 to July 2012. Patients with all age groups, both genders with decompensated liver cirrhosis having the following criteria [lower limb edema, hyperbilirubinemia, jaundice, bleeding tendency, ascites, gastrointestinal (GI) bleeding, spontaneous bacterial peritonitis (SBP) and hepatic encephalopathy] were included into this study. Patients with renal failure (serum creatinine $\geq 1.5 \mathrm{mg} / \mathrm{ml}$ ) or without renal failure (serum creatinine $<1.5 \mathrm{mg} / \mathrm{ml}$ ) were included. Patients with compensated liver cirrhosis or who refused to participate were excluded from the study. All patients were subjected to the following; baseline assessment by history, clinical examinations and investigations.

History Taking: Data were collected using questionnaire including; personal data of the studied patients (age, gender, residence, occupation and smoking history or other special habits of medical importance) and full medical past history [e.g. Diabetes mellitus (DM), hypertension (HTN)].

Clinical Examinations: General, chest, heart, neurological, and abdominal examinations were performed to all patients.

Outcome Measures: Child-Pugh score was performed to assess the prognosis of liver disease. MELD score was assessed to predict survival.

Laboratory Studies: These laboratory investigations were done for all the studied patients; PT, CBC (Sysmex K-80o cell counter), serum creatinine, urea and uric acid, liver function tests (ALT, AST, serum direct and 
indirect bilirubin, serum albumin, total protein, and alkaline phosphatase) and random blood glucose (Dimension ES chemical auto-analyzer), complete urine analysis, serum and urinary sodium, and diagnostic taping for ascetic fluid for chemistry and cytology.

Imaging Studies: Upper GI endoscopy was performed for hematemesis and melena cases. Pelvi-abdominal ultrasonography was performed for assessment of liver cirrhosis, kidney echogenicity, spleen, pancreas and ascites.

Study Procedure: In every patient, a standardized diagnostic program, including physical examination, blood chemistry, urine analysis and abdominal ultrasound was performed. Infections or bleeding complications as well as past intake of nephrotoxic drugs were documented. Current medication with such drugs or with diuretics was immediately stopped. In patients with suspected HRS, a volume expansion with $1500 \mathrm{ml}$ of isotonic saline was performed in accordance with the published diagnostic criteria. The patients were then classified according to the cause of renal failure (1hypovolemia; 2- pre-renal failure due to bacterial infection; 3- renal parenchymal disease; 4- excess use of diuretics or intake of nephrotoxic drugs (drug-induced); and 5- HRS). Infections, underlying liver disease and kidney dysfunction were treated according to the current standard of care, i.e. patients with infections received systemic antibiotics and patients with upper intestinal bleeding received vasoactive treatment, prophylactic antibiotics, and emergency therapeutic endoscopy. Patients with HRS were treated according to the current recommendations (vasoactive drugs, i.e. terlipressin or octreotide/ midodrine, plus albumin). The patients were followed until death (mortality rate was $12.8 \%$ ), or end of observation (mean followup period of $6.62 \pm 2.0$ months). The MELD score was calculated by the formula: $9.6 \times \log ($ creatinine $\mathrm{mg} / \mathrm{dl})+3.8 \times \log$ (bilirubin $\mathrm{mg} / \mathrm{dl})+11.2 \times \log (\mathrm{INR})+6.4^{(7,8)}$.

\section{Statistical Analysis}

Gathered data were processed using Statistical Package of Social Sciences version 20 (IBM SPSS ver. 20). Quantitative data were expressed as median or means \pm standard deviation (SD) as appropriate. Qualitative data were expressed as frequency (numbers) and percentages. The results for all categorical variables were given in the form of rates (\%). The independent data of the study were conducted and analyzed. Assessment of predictors of renal failure in patients with decompensated liver cirrhosis was performed by logistic regression analysis model. In order to identify factors significantly associated with renal failure, we included the parameters in the logistic regression model. For each parameter, odds ratios (OR) and 95\% confidence intervals $(\mathrm{Cl})$ are given. A probability value ( $p$-value) $<0.05$ was considered statistically significant.

\section{Results}

As shown in Table 1, the mean age of the patients was $56.6 \pm 6.5$ years with a range of 48-67 years. There was a higher frequency of males than females in the studied patients (68.6\% versus $31.4 \%$, respectively). The majority of the patients resided in rural areas (58.1\%), had no history of smoking (75.6\%), and had no co-morbidities (54.6\%). The most frequent cause of liver cirrhosis was HCV (41.9\%), followed by HBV (24.4\%). The most frequent cause of decompensating liver was tense ascites (32.5\%), followed by variceal bleeding (25.6\%). The prevalence of renal failure in the studied patients with decompensated liver cirrhosis was $38.4 \%$. 
Table 1: Patients' Demographic data

\begin{tabular}{|c|c|}
\hline Variables & Patient $(\mathrm{n}=86)$ \\
\hline Age (years) & $56.6 \pm 6.5$ \\
\hline Gender & \\
\hline Male & $59(68.6 \%)$ \\
\hline Female & $27(31.4 \%)$ \\
\hline Residence & \\
\hline Urban & $36(41.9 \%)$ \\
\hline Rural & $50(58.1 \%)$ \\
\hline Smoking & \\
\hline No & $65(75.6 \%)$ \\
\hline Yes & $21(24.4 \%)$ \\
\hline Co-morbidities & \\
\hline None & $47(54.6 \%)$ \\
\hline $\mathrm{Dm}$ & $29(33.7 \%)$ \\
\hline HTN & $10(11.6 \%)$ \\
\hline Liver cirrhosis etiology & \\
\hline HBV & $21(24.4 \%)$ \\
\hline $\mathrm{HCV}$ & $36(41.9 \%)$ \\
\hline Both & $19(22.1 \%)$ \\
\hline Others & $10(11.6 \%)$ \\
\hline Decompensating causes & \\
\hline Ascites & $28(32.5 \%)$ \\
\hline SBP & $16(18.6 \%)$ \\
\hline Encephalopathy & $11(12.8 \%)$ \\
\hline Bleeding & $22(25.6 \%)$ \\
\hline Hyperbilirubinemia & $9(10.5 \%)$ \\
\hline Renal failure & \\
\hline Yes & $33(38.4 \%)$ \\
\hline No & $53(61.6 \%)$ \\
\hline Mortality & \\
\hline Yes & $11(12.8 \%)$ \\
\hline No & $75(87.2 \%)$ \\
\hline Hospital stay (days) & $21.6 \pm 8.6$ \\
\hline Child-Pugh score & $12.6 \pm 1.9$ \\
\hline MELD score & $25.6 \pm 8.9$ \\
\hline
\end{tabular}

$\mathrm{DM}=$ diabetes mellitus; $\mathrm{HTN}=$ hypertension; $\mathrm{HBV}=$ hepatitis $B$ virus; $H C V=$ hepatitis $C$ virus; $S B P=$ spontaneous bacterial peritonitis; MELD=Model for End-stage Liver Disease.

The mortality rate among the studied patients was $12.8 \%$. The mean duration of hospital stay was $21.6 \pm 8.6$ days. The mean Child-Pugh score was $12.6 \pm 1.9$, while the mean MELD score was $25.6 \pm 8.9$ (Table 1 ). The causes of renal failure in the studied patients were as follows (from higher to lower frequency); hypovolemia $(n=11$, $33.3 \%)$, bacterial infection $(n=8,24.2 \%)$, parenchymal renal disease $(n=7,21.2 \%)$, drug-induced $(n=5,15.2 \%)$, and HRS $(n=2$, 6.1\%) (Figure 1).

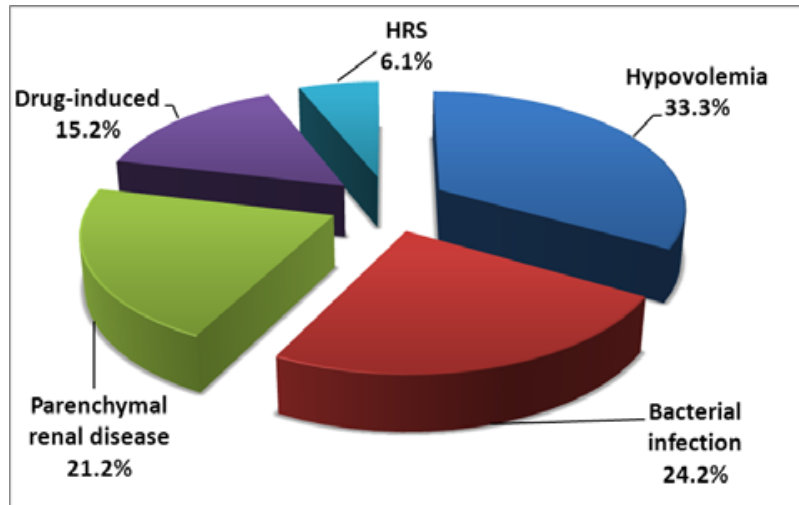

Figure 1: Causes of renal failure in the studied patients

Table (2) shows the comparison between the patients with and without renal failure. There were statistically significant higher mean age, higher mean duration of hospital stay and higher mean MELD score in the studied patients with renal failure than patients without renal failure $(p=0.001)$. Also, there were higher frequencies of smoker patients, patients with SBP, and patients with variceal bleeding in the studied patients with renal failure than in patients without renal failure $(p=0.01)$, while there were higher frequency of patients with tense ascites in the studied patients without renal failure than in patients with renal failure $(p=0.01)$. Table (3) shows a logistic regression analysis model for assessment of predictors of renal failure in patients with decompensated liver cirrhosis. Significant predictors include age $>55$ years (odds ratio $(O R)=3.5), S B P(O R=4.8)$, variceal bleeding ( $O R=14.7)$, urine sodium ( $O R=$ $11.8)$, serum sodium $(O R=7.9)$, and $M E L D$ score $>25(\mathrm{OR}=15.6)$.

\section{Discussion}

In addition to the degree of liver failure, kidney function is clearly one of the most important prognostic factors in patients 
with advanced cirrhosis ${ }^{(4,14,15)}$. Serum creatinine is the only component of MELD score for the prediction of survival in cirrhotic patients and it is not directly dependent on hepatic function $^{(9,10)}$. However, the MELD score does not reflect the cause of renal impairment. As, in cirrhotic pati-ents, many different conditions, including HRS may lead to renal impairment, it is important to establish whether the cause of kidney dysfunction plays a prognostic role in cirrhotic patients with renal failure.

Table 2: Comparison between patients with and without renal failure regarding the studied parameters

\begin{tabular}{|c|c|c|c|}
\hline Variables & $\begin{array}{l}\text { Renal failure } \\
\quad(n=33)\end{array}$ & $\begin{array}{l}\text { No renal failure } \\
\qquad(\mathrm{n}=53)\end{array}$ & p-value \\
\hline Age (years) & $59.4 \pm 5.2$ & $53.6 \pm 4.8$ & $0.001 *$ \\
\hline Sex & & & 0.2 \\
\hline Male & $20(60.6 \%)$ & $39(73.6 \%)$ & \\
\hline Female & $13(39.4 \%)$ & $14(26.4 \%)$ & \\
\hline Residence & & & 0.3 \\
\hline Urban & $11(33.3 \%)$ & $25(47.2 \%)$ & \\
\hline Rural & $22(66.7 \%)$ & $28(52.8 \%)$ & \\
\hline Smoking & & & $0.001 *$ \\
\hline No & $15(45.5 \%)$ & $50(94.3 \%)$ & \\
\hline Yes & $18(54.5 \%)$ & $3(5.7 \%)$ & \\
\hline Co-morbidities & & & 0.1 \\
\hline None & $14(42.4 \%)$ & $33(62.2 \%)$ & \\
\hline $\mathrm{DM}$ & $13(39.4 \%)$ & $16(30.2 \%)$ & \\
\hline HTN & $6(18.2 \%)$ & $4(7.5 \%)$ & \\
\hline Causes of Decompensation & & & \\
\hline Tense ascites & $2(6.1 \%)$ & $26(49.1 \%)$ & $0.001 *$ \\
\hline SBP & $11(33.3 \%)$ & $5(9.4 \%)$ & $0.01 *$ \\
\hline Hepatic encephalopathy & $1(3.1 \%)$ & $10(18.9 \%)$ & 0.07 \\
\hline Variceal bleeding & $18(54 \cdot 5 \%)$ & $4(7.5 \%)$ & $0.001 *$ \\
\hline Hyperbilirubinemia & $1(3.1 \%)$ & $8(15.1 \%)$ & 0.2 \\
\hline Urine sodium & & & $0.001 *$ \\
\hline$\geq 10 \mathrm{mEq} / \mathrm{L}$ & $27(81.8 \%)$ & $53(100 \%)$ & \\
\hline$<10 \mathrm{mEq} / \mathrm{L}$ & $6(18.2 \%)$ & 0 & \\
\hline Serum sodium & & & $0.001 *$ \\
\hline$\geq 130 \mathrm{mEq} / \mathrm{L}$ & $29(87.9 \%)$ & $53(100 \%)$ & \\
\hline$<130 \mathrm{mEq} / \mathrm{L}$ & $4(12.1 \%)$ & 0 & \\
\hline Mortality rate & $9(27.3 \%)$ & $2(3.8 \%)$ & $0.001 *$ \\
\hline hospital stay (days) & $28.6 \pm 6.8$ & $14.6 \pm 10.3$ & $0.001 *$ \\
\hline Child-Pugh score & $12.2 \pm 1.9$ & $12.5 \pm 2.3$ & 0.5 \\
\hline MELD score & $30.2 \pm 10.8$ & $21.5 \pm 4.3$ & $0.001^{*}$ \\
\hline
\end{tabular}

*=Significant, SBP=spontaneous bacterial peritonitis, MELD=Model for End-stage Liver Disease.

Although in our present study, HRS was the least common etiology of kidney failure; our data show that only $6.1 \%$ of the patients with cirrhosis and renal impairment have HRS. In our cohort, hypovolemia (33.3\%) was the most common finding, followed by bacterial infection (24.2\%), parenchymal renal disease (21.2\%), and drug-induced kidney dysfunction (15.2\%). However, these data will probably vary between different 
centers, as, particularly in tertiary care centers; the selection of patients in referring hospitals will have a major impact on the relative proportion of patients with HRS. Our data clearly show that in patients with renal failure, the prognosis is worse than in patients with cirrhosis and without kidney dysfunction. In fact, in our present study as well as in previous studies, patients with renal dysfunction (including HRS) generally had very high MELD scores of 20 or above $^{(6)}$. Such high MELD scores are asso- ciated with high mortality rates of $75 \%$ or more ${ }^{(8)}$. However, our data demonstrate that not only the severity of disease, assessed by the MELD score, but also the age $>55$ years, SBP, variceal bleeding, urine sodium, and serum sodium are independent predictors of renal failure in patients with decompensated liver cirrhosis. This confirms the results of Allesandria et $\mathrm{al}^{(6)}$ who conceivably demonstrated that, the MELD score was a significant predictor.

Table 3: Logistic regression analysis model for assessment of the predictors of renal failure in patients with decompensated liver cirrhosis $(n=86)$

\begin{tabular}{|l|ccc|}
\hline Variables & OR & $95 \% \mathrm{Cl}$ & $\mathrm{p}$-value \\
\hline Age $>55$ years & 3.5 & $1.1-7.6$ & $0.001^{*}$ \\
Smokers & 2.3 & $1.2-50.6$ & 0.07 \\
Tense ascites & 0.06 & $0.01-0.3$ & $0.001^{*}$ \\
SBP & 4.8 & $1.3-19.5$ & $0.01^{*}$ \\
Variceal bleeding & 14.7 & $3.9-66.5$ & $0.001^{*}$ \\
Urine sodium <10mEq/L & 11.8 & $1.3-102.9$ & $0.001^{*}$ \\
Serum sodium <130mEq/L & 7.9 & $0.8-73.7$ & $0.001^{*}$ \\
MELD score $>25$ & 15.6 & $4.3-8.6$ & $0.001^{*}$ \\
\hline
\end{tabular}

*Significant p-value, SBP=spontaneous bacterial peritonitis, MELD=Model for End-stage Liver Disease

Renal dysfunction due to other conditions is specifically addressed by our present study: we prospectively investigated an unselected, consecutive cohort of cirrhotic patients with elevated serum creatinine irrespective of the cause of kidney dysfunction. Our data clearly demonstrate that the presence of age >55 years, SBP, variceal bleeding, low urine and serum sodium have an independent prognostic relevance for these patients which add a significant prognostic information to the MELD score.

\section{Conclusion}

We conclude that renal failure is prevalent in Egyptian patients with decompensated liver cirrhosis. The MELD score, age >55 years, SBP, variceal bleeding, urine sodium, and serum sodium, are the most important reliable predictors of renal failure in these patients.

\section{References}

1. Ginès $P$, Cárdenas $A$, Schrier RW. Liver disease and the kidney. In: Schrier RW, editor. Diseases of the kidney and urinary tract. 8th Ed. Philadelphia: Lippincott Williams \& Wilkins, 2007: 2179-2205.

2. Nair S, Verma S, Thuluvath PJ. Pretransplant renal function predicts survival in patients undergoing orthotopic liver transplantation. Hepatol-ogy 2002; 35 (5):1179-1185.

3. Gines $P$, Guevara $M$, Arroyo V, Rodés J.Hepatorenal syndrome. Lancet 2003; 362 (9398): 1819-1827.

4. Schepke M, Appenrodt B, Heller J, Zielinski J, Sauerbruch T. Prognostic factors for patients with cirrhosis and kidney 
dysfunction in the era of MELD: results of a prospective study. Liver Int $2006 ; 26$ (7): 834-839.

5. Arroyo V, Gines P, Gerbes, Dudley FJ, Gentilini P, Laffi G, Reynolds TB, RingLarsen $\mathrm{H}$, Schölmerich Jl. Definition and diagnostic criteria of refractory ascites and hepatorenal syndrome in cirrhosis. Hepatology 1996; 23 (1): 164-176.

6. Allesandria $C$, Ozdogan $O$, Guevara $M$, Restuccia $T$, Jiménez $W$, Arroyo $V$, Rodés J, Ginès P.. MELD score and clinical type predict prognosis in hepatorenal syndrome: relevance to transplantation. Hepatology 2005; 41 (6): 1282-1289.

7. Arroyo V, Colmenero J. Ascites and hepatorenal syndrome in cirrhosis: pathophysiological basis of therapy and current management. J Hepatol 2003; 38 (Suppl. 1): S69-89.

8. Moreau R, Durand F, Poynard T, Duhamel C, Cervoni JP, Ichaï P, Abergel A, Halimi C, Pauwels $M$, Bronowicki JP, Giostra $E$, Fleurot C, Gurnot D, Nouel O, Renard P, Rivoal M, Blanc $P$, Coumaros D, Ducloux $S$, Levy S, Pariente A, Perarnau JM, Roche $J$, Scribe-Outtas $M$, Valla $D$, Bernard $B$, Samuel D, Butel J, Hadengue A, Platek A, Lebrec D, Cadranel JF. Terlipressin in patients with cirrhosis and type 1 hepatorenal syndrome: a retrospective multicenter study. Gastroenterology 2002; 122 (4): 923-930.

9. Kamath PS, Wiesner R, Malinchoc $M$, Kremers $W$, Therneau TM, Kosberg CL, D'Amico G, Dickson ER, Kim WR. A model to predict survival in patients with end- stage liver disease. Hepatology 2001; 33 (2): 464-470.

10. Wiesner R, Edwards E, Freeman R, Harper A, Kim R, Kamath P, Kremers W, Lake J, Howard T, Merion RM, Wolfe RA, Krom R; United Network for Organ Sharing Liver Disease Severity Score Committee.. Model for end-stage liver disease (MELD) and allocation of donor livers. Gastroenterology 2003; 124 (1): 91-96.

11. Schepke $M$, Roth F, Fimmers R, Brensing KA, Sudhop T, Schild HH, Sauerbruch TI. Comparison of MELD, Child-Pugh and Emory model for the prediction of survival in patients undergoing transjugular intrahepatic portosystemic shunting (TIPS). Am J Gastroenterol 2003; 98 (5): 1167-1174.

12. Moreau $R$, Lebrec $D$. Acute renal failure in patients with cirrhosis: perspectives in the age of MELD. Hepatology 2003; 37 (2): 233-43.

13. Gines P, Cardenas A, Arroyo V, Rodés J. Management of cirrhosis and ascites. $\mathrm{N}$ Engl J Med 2004; 350 (16): 1646-1654.

14. Gines $P$, Martin $P$ Y, Niederberger $M$. Prognostic significance of renal dysfunction in cirrhosis. Kidney Int 1997; 52 (Suppl. 61): 77-82.

15. Fernandez-Esparrach $G$, Sanchez-Fueyo A, Gines P, Uriz J, Quintó L, Ventura PJ, Cárdenas $A$, Guevara $M$, Sort $P$, Jiménez $\mathrm{W}$, Bataller R, Arroyo $\mathrm{V}$, Rodés J.. A prognostic model for predicting survival in cirrhosis with ascites. J Hepatol 2001; 34 (1): 46-52. 